\title{
How Best to Enable Support for Children Affected by HIV/AIDS? A Policy Case Study in Tanzania
}

\author{
Masuma Mamdani, Rakesh Rajani and Valerie Leach ${ }^{*}$
}

\begin{abstract}
1 Background
Tanzania has a population of about 40 million people, half of whom are children (herein defined as under the age of 18 years). Poverty is pervasive, especially in the rural areas where 75 per cent of the population lives. About 36 per cent of Tanzanians live below the basic needs poverty line (2000/1), i.e. well under $\$ 1$ a day. Nearly 20 per cent (around 4 million children) live below the food poverty line which is 80 per cent of the basic needs poverty line (RAWG 2003). Their income cannot provide enough food to satisfy their basic minimum nutritional requirements.
\end{abstract}

Despite encouraging trends in GDP growth since 1993, household budget surveys have shown no change in the proportion of rural households who are poor, and the perceptions of the majority of Tanzanians across all income groups, including the least poor, are that their living standards have been stagnant or declining. Income disparities have grown over the last two decades both between rural and urban households and among urban households (RAWG 2007).

Around 7 per cent of Tanzanian adults are living with HIV. The epidemic has an enormous impact in communities in Tanzania (TACAIDS, NBS and ORC Macro 2005). Some households and communities fare better than others, depending on a range of factors to do with their own endowments and the wider social and economic situation in which they find themselves, but in a context of widespread poverty, chronic impoverishing forces and shocks may push the vulnerable to a deeper level of poverty (de Waal et al. 2004)
Rural children are the most vulnerable to shocks and stresses occasioned by poor living conditions, malnutrition, ill-health and HIV/AIDS, particularly in rural areas (Leach 2008). Close to 10 per cent of all children, roughly 2 million children, have lost one or both parents. Projected estimates also suggest that there were over 6.6 million poor children in 2006.

Policies are important to promote child wellbeing. But their importance in affecting actual wellbeing varies - some draw political attention, get translated into programmes, attract resources and are implemented. Others do not. Why is this? How is support for children affected by HIV best enabled, given chronic rural poverty and the constraints of scarce resources and often weak institutional structures? Which policies have the best chance of success?

Policies are often analysed statically, on the basis of evidence for the problem, and internal technical logic and argument. But this may explain little about policies' ability to bring change. To understand what may most effectively bring about change, it may be more instructive to study policy in practice, and the contextual factors that make change more or less effective.

This article analyses three recent policy/programme developments regarding child wellbeing in Tanzania and examines the political 'drivers of change' that influence policy and action on child wellbeing. The first part focuses on universal primary education and explores the politics of policymaking, and the respective roles of citizens, government and donors 
Figure 1 The flow of primary and secondary education funds

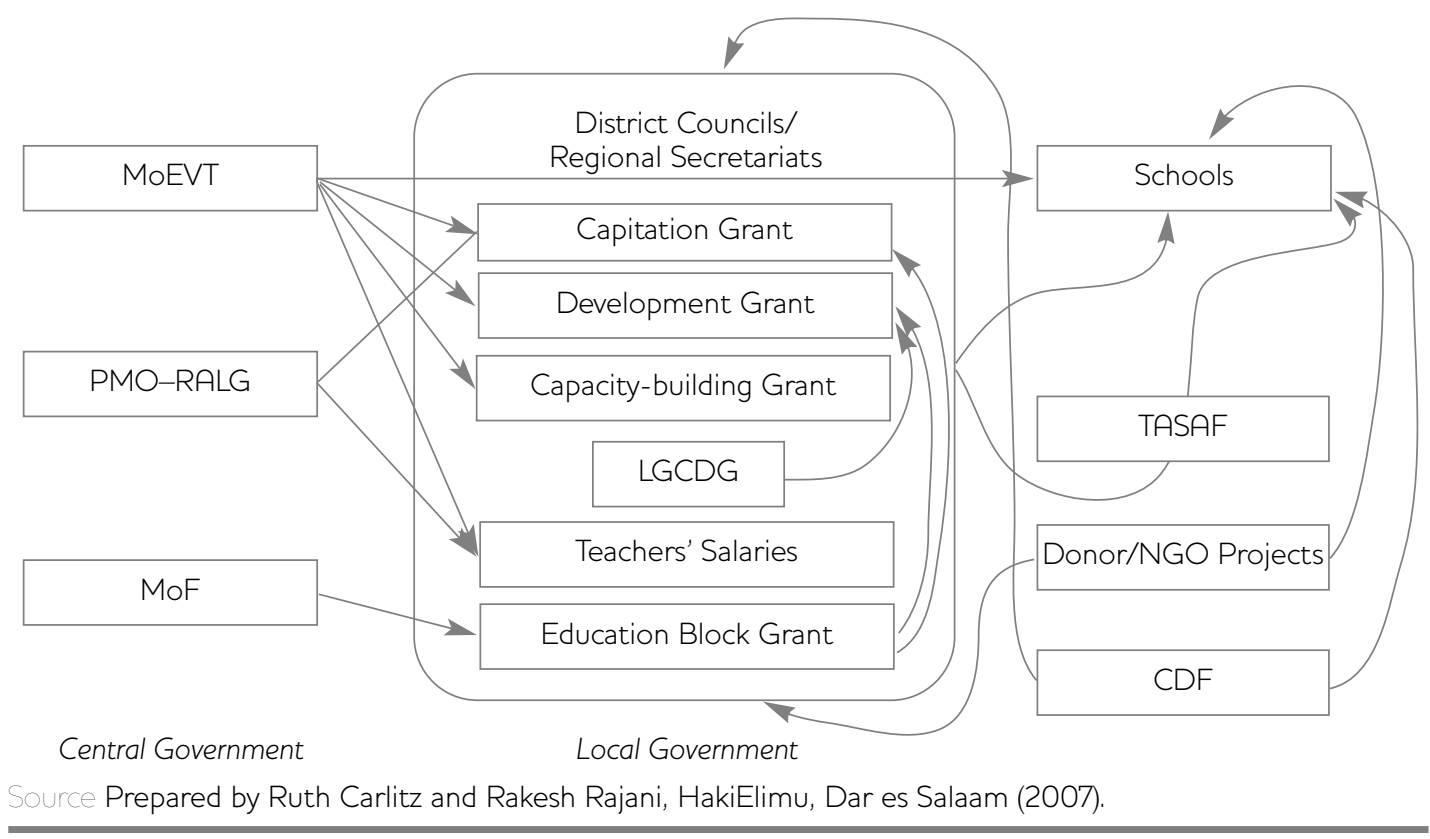

that influenced this policy. Section two provides a historical analysis of processes in place towards the development of a children's statute in Tanzania and explores the underlying reasons behind why there has been little change despite concerted efforts. The final part addresses the viability of the social protection model that is presently being promoted to protect the most vulnerable children (MVC) in Tanzania.

\section{Universal primary education}

The Government of Tanzania has received domestic and international recognition for its achievements in primary education, which has constituted the country's biggest overall policy commitment in the last decade in terms of scale, scope and budget. Under the Primary Education Development Plan 2002-06 (PEDP), massive investments were made in the sector across the country. The overall budget for basic education more than doubled in five years (in nominal terms), through both improved domestic revenue collection and increased donor funding, ${ }^{1}$ allowing resources disbursed to the school level to increase at least five-fold from less than $\$ 1$ per pupil to over $\$ 5$ per pupil per annum (URT 2001;

HakiElimu 2007a). Mandatory primary school fees and contributions were abolished. The number of teachers increased by 50 per cent, and over 41,000 new classrooms were built (HakiElimu 2007b). This allowed an additional 3 million children to be enrolled in primary school by 2006.

While major household and demographic survey data since PEDP are not yet available, it is likely that with an overall net enrolment rate of 96 per cent in 2006, a large proportion of the poor and vulnerable children, including those affected by AIDS and others whose caregivers have diminished capabilities to secure basic livelihoods have been signed up for primary school. The well-established benefits and returns of education for personal and community wellbeing can be assumed to accrue to poor and vulnerable children. These achievements represent dramatic movement in a sector that had stagnated for two decades. The further advantage of the universal approach is that it benefits entire communities at scale, without the tensions and large administrative costs associated with targeted programmes.

PEDP has some of the most critical factors needed to engender concerted action on child wellbeing. It was able to marshal considerable national and international resources, bring together key constituencies to work on a common purpose after decades of policy neglect and under-funding, ${ }^{2}$ and capture public imagination 
and support. Assistance to education is perhaps the single most important public policy measure that assists the most vulnerable children in Tanzania. In budgetary terms, universal primary education is perhaps the largest social transfer that assists all children in Tanzania (Brar 2006).

However, while primary education successfully 'includes' large numbers of children, it fails to live up to its full promise and potential. The capitation grant, set at $\$ 10$ per enrolled pupil per annum, perhaps the most powerful component of PEDP, has not brought about the expected quality improvements in a fair and reliable manner. 'Leakage', in which funds disbursed do not reach the school level, due to poor ministration, reallocation, delays, or corruption, may be part of the problem (REPOA 2004).

The system is overly complex, a 'spaghetti-like mess'! (Figure 1). The single education grant is disbursed by multiple ministries using different criteria, timeframes and mechanisms, making it impossible for local government officials and teachers to predict with any reasonable certainty how much money they will receive, when and for what, wreaking havoc to their plans and budgets. Parents, pupils and teachers are similarly unable to persue their claim to entitlements (Carlitz 2007). Moreover, the simple formula-based allocation designed to correct historical disparities in fund disbursements appears not to have worked as hoped.

Significant inequities remain entrenched. Those left out include a disproportionately high number of poorer and vulnerable children, and the potential of education to improve longer-term quality of life and livelihood prospects is likely to be limited. Large geographical disparities persist in teacher distribution, across districts and among schools. Classrooms are overcrowded and teaching is geared specifically to the primary school leaving exam. The flow of education funds to schools is unpredictable. Provisions for special needs are virtually unheard of (see Sundet 2007; HakiElimu 2007a; TEN/MET 2006; RAWG 2007). In this context the well-to-do have tended to opt out of public schooling by sending their children to relatively better functioning private schools, with the potential of undermining social cohesion.

\subsection{What are the lessons learned from PEDP?}

Why did PEDP work when it did, and why did it fail where it failed? A systematic analysis of these questions is beyond the scope of this article. Nonetheless, five key lessons can be learned from the PEDP experience.

First, research evidence and lobbying on their own were insufficient to make a change. The data to show that there was a crisis in education was known and presented for years before PEDP, but it did not succeed in determining new policy or altering implementation. However, credible evidence proved crucial in undergirding an effective strategy when embedded in an informed political dynamic. The core challenge here becomes how to effectively engage concerned citizens to foster the creation of public understandings and an informed public debate that transforms the desire to have impact into a shared enterprise.

Second, the influence of donors, while large, tends to be exaggerated, even in Tanzania where donors contributed over 40 per cent of the 2007/8 national budget. Several factors contribute to donor limitations, including reluctance to act on political incentives and dynamics; limited knowledge of the situation on the ground and of the political forces at play; and the imperative to disburse funds which creates an incentive to sweep critical challenges under the carpet. Despite these limitations, a strategic donor that understands local politics can play a vital role when the time is ripe, as in relation to abolition of primary school fees and contributions in Tanzania.

Third, effective change is unlikely to be achieved by increased funding and technocratic solutions alone. Instead, there is a need to better understand and engage with a citizen-centred political dynamic. Interventions such as enrolling children, building classrooms and raising funds are relatively easier to accomplish than improving classroom teaching and development of skills at scale. 'Capacity building' in this instance is less about establishing systems, manuals and training, and more about enabling people to develop a vital resourcefulness to discern power relations and act creatively.

Fourth, leadership is key and there are no shortcuts around it. Leadership here constitutes the ability to craft a path that acknowledges achievements but then moves swiftly to deal with the challenges, and that values critics and outside-the-box thinkers as pointing to making things even better. 


\section{Table 1 Chronology of Tanzanian efforts to develop a children's statute}

July $1986 \quad$ Law Commission notifies Minister that it has set up a working group

September 1990 President signs the CRC at World Summit for Children

$1991 \quad$ Law Commission's working group completes its study

July $1991 \quad$ National Assembly ratifies CRC

April $1994 \quad$ Law Commission Report published

December 1998 Permanent Secretary, Ministry of Justice and Constitutional Affairs establishes committee to review three Law Commission reports on: children (1994), marriage (1994), succession/inheritance (1995)

1999/2000 Law Reform Commission submits report to Ministry of Justice and Constitutional Affairs on drafting a Children's bill

October 2001 Workshop to discuss committee's report ('Makaramba report')

Decision by Ministry of Justice and Constitutional Affairs to prepare a cabinet paper before proceeding with legislative process

June $2002 \quad$ Workshop of Department of Social Welfare to review laws related to child rights

2003 Submission by National Network on Children of elements and principles for new legislation for children (Andersson and Mashamba)

Decision that a further consultation process is needed/white paper process

Plans and budget for white paper/consultation submitted for funding

Decision to postpone until after elections held end 2005

Early $2008 \quad$ Presentation to Cabinet of proposed draft legislation

Cabinet decision that further public consultation is needed

Last, accountability and political pressure are essential. Education was fortunate in that there was a combination of public pressure and donor readiness. A citizen-centred political dynamic was key to effecting change. This underlines the importance of a social mobilisation approach as opposed to apolitical technical development programmes that dominate programmes for children affected by AIDS.

Public pressure is often vital to initiating accountable action, and continuing to sustain reforms over a longer term.

In the PEDP story, concerted public pressure was often the major force that tipped the scales. Public pressure was instrumental in PEDP's initiation, abolishing school fees, putting children with disabilities on the education agenda, improving timeliness of teachers' salaries and strengthening scrutiny of expended funds at local levels. But the limits of citizens' action is shown by the limited progress in several of these areas, including making schools more inclusive of people with disabilities, or ending corporal punishment.

Public pressure results both in increased awareness of the issue and is also targeted towards levers for change. Those who lead and manage public pressure well have developed the art of making unorthodox connections - such as building alliances between progressive media and trades unions, sniffing out opportunities, discerning the allies and resistors in positions of influence, and exercising political judgement.

\section{Children's statute}

Tanzanian efforts to develop a children's statute to provide effect to the relevant provisions in the Constitution and in accord with the United Nations Convention on the Rights of the Child (CRC) started in 1986 (Table 1) with a review of existing legislation on children. The Tanzania National Assembly ratified the CRC in 1991. In the ensuing years, the commission responsible for law reform presented 
papers, and workshops have been held in which varying commitments were expressed to enact new legislation (Andersson and Mashamba 2003; Makaramba 2001; URT 1994). However, over 20 years since these efforts began, legislation affecting children is still haphazard and fragmented (Ruebangira and Mramba 2007; UN 2006). In many communities, customary law prevails which may not be in children's best interests. A unified statute for children would set the standard for the realisation of children's rights.

The reviews have made similar recommendations, particularly on issues that have been the major concerns of the public and gender and child rights activists (URT 2002; Makaramba 2001). Why then has there been little progress in bringing draft legislation to the National Assembly?

What was the significance of Tanzania's ratification of the CRC? While ratification of international instruments technically indicates the country's acceptance of internationally constructed principles and a desire to adopt an international code in its own laws, in practice ratification appears to have been little more than 'signing a piece of paper'. It may be that states such as Tanzania agree to international codes because this is perceived as desirable in the eyes of an international community on whom the country is dependent for funding. The authorities can easily agree precisely because they can get away with not having to implement changes in practice, and possibly because they have not fully fathomed the implications of changes implied by such agreements in the first place. $A$ lesson here is that international instruments in themselves have little power to affect wellbeing in practice, and we are reminded of the large gap between policy and practice.

The delay is not attributable to technical reasons involved in drafting a statute. Matters of children are seen as belonging to a private, domestic domain that is sensitive for public policy. But while thorny cultural aspects regarding the age of children, socialisation, physical treatment of children, etc. are real, the broad education reforms discussed in the first section and the speed with which legislation on child sex abuse was adopted, in response to public outcry suggest that the more compelling factors lie elsewhere.

The struggle for a children's statute is made more difficult because children themselves have not been involved in this process as is their right. Their council is still not a legal entity. Children lack strong champions who can draw other constituencies into supporting them. Even where there is public concern, this does not translate into legislative pressure because few see the enactment of a new law as making a practical difference in meeting needs or realising rights. The crux of the issue may be that the need for a law on children has never enjoyed a groundswell of concern among parents, politicians and donors alike, such as that enjoyed by education, or broad awareness and organised civil society and feminist activism, as seen in the enactment of the law on sexual offences.

One cautionary note is that even if new legislation were to be enacted, its implementation would probably be haphazard and uncertain without consistent public expectation and pressure for change. Effective advocates are needed within government to move the process along. Pressure is also needed from a social movement for children's rights. Intermittent efforts of Save the Children (UK) and UNICEF have brought together local non-governmental organisations (NGOs) with government ministries and children. Nonetheless, there is general agreement that an effective coordinated voice for children's rights is lacking, and without it, progress towards the realisation of children's rights, including legislating a children's statute, is less likely.

\section{Social protection of the most vulnerable children}

Tanzania lacks a public system for adequately supporting its most vulnerable children. Formal socia protection arrangements to reach these children or their caretakers, are either not in place, or are insufficient. Households and communities are not only the first line of response in the provision of care to children affected by HIV/AIDS, but remain the only line of response for most children (Charwe et al. 2004; RAWG 2004)

In June 2001, Tanzania committed itself to the UN General Assembly Special Session (UNGASS) obligations for an effective scaled-up national response to orphans and vulnerable children. The current MVC programme, developed by the Department of Social Welfare, is part of a major attempt to fulfil the UNGASS obligations (GoT 2006). However, while the HIV/AIDS epidemic in Tanzania may have been the catalyst for developing 


\section{Box 1 Views of the most vulnerable children, their carers and community leaders}

Children from Magu district would have appreciated receiving sleeping beds with bed nets to prevent them from catching malaria and clean and safe water for drinking and domestic use. The children said their caregivers were not able to provide for their basic needs because of 'inadequate means to earn income, including inadequate access to land, or because of old age'. According to children from Singida district, the 'relatively better-off members of the community are happy with increased numbers of vulnerable children in the village as labour becomes less expensive'. The more vulnerable, the greater the willingness to work at any wage in order to survive - one of the reasons why members of the community are unwilling to contribute to the programme. In Bagamoyo district, children noted that 'support was said to be provided only during the Islamic festivities when Moslems provide philanthropic offerings to the village committee for the most vulnerable children so that they can also enjoy the festivity'. Children from Makete district continue to work 'carrying timber and charcoal trading, to help meet their needs'. Children in Songea district cope by taking 'refuge in their relatives' households'.

the national programme and plan for vulnerable children, the government recognised the need to address the needs of all vulnerable children, irrespective of the reasons for their vulnerability, as opposed to only targeting those orphaned or made vulnerable by HIV/AIDS. This respects the rights of all children and also complies with the CRC.

The MVC programme is small in scale and modest in impact. About 160,000 MVCs are receiving support through programmes which use community-based targeting for the most vulnerable, destitute children. Children are provided ad hoc support in kind clothing, school uniforms, contributions for community health insurance schemes, materials for shelter improvements (Daniel 2007; Mhamba et al. 2007; Littrell 2006). While most of the children and caregivers feel that the MVC programme is important, the support provided is unpredictable, inadequate and inconsistent (see Box 1).

The practice of mobilising resources locally, and having communities contribute financially or in kind, has at times exacerbated local differentiations and existing disparities. The poorest people, those most in need of support, are expected to contribute in ways that the better-off do not. With many demands on communities for contributions to development programmes, especially those related to education and water, those programmes with the strongest political and governmental pressures take priority, and those with obvious external support may then be marginalised in local resourcing.
This MVC response is reliant on a few external donors, notably PEPFAR (US President's Emergency Plan for AIDS Relief), leaving it vulnerable to donor policy shifts. Dependence on HIV/AIDS-specific funding is of particular concern.

A review of MVC programmes reveals a 'spaghetti plate' of initiatives, mechanisms, funds and bodies, which demonstrate that the core problem is not lack of effort and funding, but the commitment of all stakeholders - donors, the state and the civil society to a coordinated, systemic response. The core question is not about the need to do something or raising more funds for it, but how to do it effectively and in a manner that recognises rights and entitlements and that is sustainable. The bewildering multiplicity of initiatives and high volumes of external funding, particularly for HIV/AIDS, may create distortions, undermine local capacity and cause as much harm as good. Local government authorities are the most important implementing stakeholder, but are constrained by insufficient resources, personnel and information, while also being overwhelmed by the multiple demands made on them.

In this context, clearly better coordination and harmonisation is needed, but this is easier said than done. One answer is to work to strengthen local government systems and budgets, rather than create standalone silos and projects. But the latter is often done precisely because government channels have been poor at responding to the needs of vulnerable children, or been effectively accountable to local 


\section{Box 2 Excerpts from focus group discussions regarding abuse and corruption by the village leaders}

... some leaders are biased and corrupt. They give priority to their relatives and friends ... You end up complaining to the ward secretary that what they are doing is not good [but] you can't prevent ... It does of course stimulate strife and conflict between those that have received and those that do not ... this situation is provoked by village leaders who only write the names of their children when registering true orphans... names are then submitted to more than one aid organisation while true orphans are left out ... the ones who are in more difficult conditions... You can also find that one whose parents died this year has his/her name written excluding one whose parents died many years ago. If you ask them they defend that the missing names are yet to be entered into the database hence, they need to wait ... other problem is that there are many orphans such that not all are covered by aid ... other unfortunate ones are always left out ... they are not chosen when aid organisations pick criteria to sieve them for aid eligibility...

Source Daniel (2007).

communities. What is needed now: short-term programmatic responses vs. long-term institutional investment in effective national systems? Historically, departments responsible for welfare and community development have been among the least effective and poorly funded, with relatively low status in relation to other sections of government. The desire to make a difference quickly and provide reports to donors therefore creates an incentive that favours international agencies' funding of projects and NGOs which are directly accountable to them. But the evidence of the long-term effectiveness of taking this route remains unclear, as does their impact on the integrity of local government and community service delivery systems. With the large amount of resources made available, it is clear that there will be some positive effect. The real question is not how can we get more attention and funding for children and AIDS or primary education in Tanzania, but rather what specific policies, mechanisms and accountabilities can be put in place to promote the wellbeing of children, in a manner that can go to scale and is lasting.

Another key issue is the debate between targeting and universalism. There is an emerging consensus that a programme of social assistance to protect the most vulnerable children is not only necessary but should be publicly provided. While centrally directed means testing may have benefits, it requires a degree of institutional functioning and sophisticated administration that is not available in Tanzania. Community-based targeting is an alternative which is being widely used in MVC programmes. Though this approach allows for better identification of the needy, it also has local political demands and prerequisites: what has to be allocated and to whom and for what reasons (see Box 2). Important administrative challenges remain, in particular in districts where supervision is weak or non-existent.

Thus even here, the approach can be inexact and socially divisive. $A$ thin layer above the most vulnerable, many more children are at risk and also deserving of support. A strategy that focuses only on the most affected may in fact be too limited and strain the capacity of those who are supporting MVC. In contrast, expanding support to local government to deliver core services such as health, education and water to all children may reach more children at risk in a manner that is cost-effective, simpler and which would enjoy broader support, as well as strengthen existing public capacities. Embedding specific criteria and mechanisms to safeguard the interests of vulnerable children within these broad services, such as inclusion of the most vulnerable children in schooling, provision of accessible water and free or affordable health services, may reach more children over a longer period at lower cost than targeting outside these mainstream service delivery channels. $A$ universal national child benefit programme, however, would entail a vast fiscal allocation far beyond existing budgetary limits.

This debate is related to the controversy on exceptionalism - how different is HIV/AIDS from other priorities in health and social arenas and to what extent does it need an explicit focus? Among donors and international bodies AIDS holds an 
exceptionally important place, as can be seen by the high volumes of global aid and the multiplicity of programmes and institutional arrangements.

The most recent public expenditure review of HIV/AIDS budgets and spending in Tanzania casts an alarming picture on the continued rapid growth in donor HIV/AIDS spending, now expected to reach US\$496.7 million in 2007/8, and accounting for 95 per cent of total government plus donor funding. The increase has been from off-budget sources of finance, and only 23 per cent of expected aid in $2007 / 8$ is included in the budget. HIV/AIDS is now taking a staggering one-third of all aid to Tanzania (IMF ODA data; TACAIDS 2008).

Many in Tanzania observe that donors have been heavily involved in driving HIV/AIDS programming in the country, including the push to create the national coordinating body, Tanzania AIDS Commission (TACAIDS), in the original creation of the MVC programme, and more recently in the drafting of the National Plan of Action and its formal adoption at the national level. There is little direct support from national resources - financial or otherwise. In spite of efforts to have support for most vulnerable children community-based, the programme is largely seen as an 'external' programme. Domestically, there is a large number of plans and NGOs focused on HIV/AIDS, but many of them have responded to the incentives created by increased funding. While it is difficult to separate out an 'organic national concern' from international influences, and while a full examination of the issue is beyond the scope of this article, there appears to be little evidence to suggest that Tanzanians would place as high a priority on this issue as the donors. This implies that programmes that are integrated rather than AIDS-exceptional will enjoy greater public support and be more sustainable.

The point here is not to exclude donor involvement. Indeed the successes of primary education discussed earlier would not have been possible without donor support. It is instructive to compare the success of the universal primary education (UPE) policy with the shortcomings of the MVC programme and the children's statute. The differences lie in two areas: the way in which the primary education crisis was a broad and explicit public concern, such that it was a popular issue and not a 'donor issue', and the manner in which the primary education reform was structured to strengthen government systems and open them up to greater public engagement and scrutiny.

\section{Conclusion}

The central concern of this article focuses on the best way to enable support for children, and especially the most vulnerable children, given limited resources and often weak administrative structures, within a keen appreciation of the policy/politics dynamic.

The primary education programme is universal, focused and simple for national institutions, and is implemented, albeit with flaws. It is also AIDS sensitive. Assistance to education is the most important public policy measure that brings real benefit to children affected by AIDS in Tanzania. Political commitment to the children's statute on the other hand, is nominal. After more than 20 years, this has yet to come to fruition and has generated mainly paperwork and workshops. Thus, even if a statute is enacted, implementation is likely to be haphazard unless there is strong and consistent public pressure. And despite enormous external funding for the MVC programme, its implementation is fraught with problems of coordination and targeting. The programme covers only a fraction of the most vulnerable and delivers very modest amounts of assistance. Unlike universal primary education, the MVC programme is seen as a 'donor issue' with limited national commitment and remote from public engagement.

While the issues remain complex, an examination of the three different cases indicates a core common lesson: initiatives that resonate with and respond to broad public concern are more likely to gain traction, exercise accountability and be sustainable. Efforts that are technically driven and overemphasise the provision of funds are unlikely to be effective because they will 'miss' the political drivers of change in the country. The most vulnerable children may need targeted assistance for specific interventions but this can only succeed within the context of universal provision of essential services. This lesson is particularly relevant for international actors seeking to do well, for it suggests the need for a nuanced engagement with politics, culture and social forces that shape priorities, implementation and accountabilities that lie at the heart of effective support for children. 


\section{Notes}

* 'Research on Poverty Alleviation (REPOA), Tanzania'. This article is a short summary of a study for the Joint Learning Initiative on Children and HIV/AIDS (JLICA) analysing three recent policies/programme developments regarding child wellbeing in Tanzania: Primary Education Reforms by Rakesh Rajani; Children's Statute by Zubeida Tumbo Masabo and Valerie Leach; and Social Protection of Vulnerable Children by Masuma Mamdani and Francis Omondi (March 2008).

\section{References}

Andersson, M. and Mashamba, C. (2003) Basic Elements and Principles to be Incorporated in a New Children Statute in Tanzania: A Requirements Paper to be Presented by NNOC to the Government Draftsman, Dar es Salaam: National Network of Organisations Working with Children in Tanzania (NNOC), May 2003

Brar, P. (2006) Local Government Public Expenditure and Financial Accountability Review (PEFAR), Washington DC: World Bank

Carlitz, R. (2007) Following the Money for Education: A Case Study in Complexity, HakiElimu Working Paper 07.8, Dar es Salaam: HakiElimu

Charwe, D.; Koroso, W.; Kaijage, F.; Calder, J.; Nyeko, J. and Dombo, M. (2004) 'A Review of the Tanzania National OVC Response Under the "National Strategic Multi-Sectoral Framework 2000-2007'”, presented at the First Technical Review of the National Multisectoral Strategic Framework on HIV/AIDS, 10-12 February, Dar es Salaam

Daniel, M. (2007) 'Humanitarian Aid to Vulnerable Children in Makete and Iringa, Tanzania', unpublished paper, Research Centre for Health Promotion, University of Bergen, Norway

de Waal, A.; Tumushabe, J.; Mamdani, M. and Kilama,

B. (2004) Changing Vulnerability to Crisis in

Tanzania: Implications for Children and UNICEF Activities, report to UNICEF Tanzania

GoT (Government of Tanzania), Ministry of Health and Social Welfare (2006) The Costed MVC Action Plan, 2006 to 2010, with support from Family Health International, USAID

HakiElimu (2007a) Education Budget Briefs Number 07.1E, Following the Money for Education, www. hakielimu.org (accessed 10 February 2008)

HakiElimu (2007b) What has Been Achieved in Primary Education? Key Findings from Government Reviews, Dar es Salaam: HakiElimu
1 Through different modalities, including World Bank credit, sector basket funds and budget support. Education constitutes the largest single budget line, and in 2006 took up about onequarter of the entire budget.

2 For state of education sector pre-PEDP, see URT (various years); Kuleana (1999); Maarifa ni Ufunguo (1999); Narayan (1998).

Kuleana Centre for Children's Rights (1999) State of Education in Tanzania: Crisis and Opportunity, Muanza, Tanzania: Kuleana Centre for Children's Rights

Leach, V. (2008) Children and Vulnerability in Tanzania. A Brief Synthesis, REPOA Special Paper 07.25, Tanzania: Research on Poverty Alleviation (REPOA), UNICEF

Littrell, M. (2006) 'Jali Watoto Initiative and AntiStigma Campaign', MEASURE Evaluation Preliminary Case Study Findings, unpublished paper Maarifa ni Ufunguo [Knowledge is the Key] (1999) 'Cost Sharing: A Case Study of Education in Kilimanjaro', unpublished manuscript, Arusha, Tanzania

Makaramba, R. (2001) Report of Proposals of the Meeting to Review Reports of the Law Reform Commission on the Law Related to Children and the Findings of the Review Committee, submitted to the Ministry of Justice and Constitutional Affairs, Dar es Salaam

Mhamba, R.; Lindeboom, W.; Omondi, F. and Leach, V. (2007) 'Social Protection in the Context of the MVC Programme in Tanzania. An Assessment of the Impact of Implementing the MVC Programme and Operation of the MVC Funds and the Potential for Scaling Up to Provide National Coverage of Social Protection for Children', unpublished report for UNICEF, Tanzania: Research on Poverty Alleviation (REPOA)

Narayan, D. (1998) Voices of the Poor: Poverty and Social Capital in Tanzania, Geneva: World Bank RAWG (Research and Analysis Working Group) (2007) Poverty and Human Development Report 2007, Dar es Salaam: Mkuki na Nyota Publishers RAWG (2004) Vulnerability and Resilience to Poverty in Tanzania: Causes, Consequences and Policy Implications. 2002/03 Tanzania Participatory Poverty 
Assessment (TzPPA): Main Report, Dar es Salaam: Mkuki na Nyota Publishers

RAWG (2003) Poverty and Human Development Report 2003, Dar es Salaam: Mkuki na Nyota Publishers

REPOA (2004) 'Tanzania Public Expenditure Tracking Study. Study of Financial and Non-Financial PEDP Flows from Central Government to Schools in 2002 and 2003', unpublished, Research on Poverty Alleviation (REPOA) and the Ministry of Finance, Government of Tanzania, Dar es Salaam

Ruebangira, M.K. and Mramba, R. (2007) An Updated Reference Document on Policy and Legal Frameworks Affecting the Realisation of Children's Rights in Tanzania, report for Research on Poverty Alleviation (REPOA), Dar es Salaam

Sundet, G. (2007) Public Expenditure Tracking Surveys: Lessons from Tanzania, Policy Brief for U4. Norway: Chr. Michelsen Institute

TACAIDS (Tanzania AIDS Commission) (2008) Tanzania Public Expenditure Review. Multi-Sectoral Review: HIV-AIDS December 2007. Final Report, prepared by Mick Foster, Cam Do, Milton Lupa and Mrs Vera Urassa Mdai on behalf of HIV/AIDS PER Working Group, TACAIDS, Ministry of Finance and Government of Tanzania
TACAIDS, NBS and ORC Macro (2005) Tanzania HIV/AIDS Indicator Survey 2003/04, Dar es Salaam: TACAIDS

TEN/MET (2006) Strengthening Education in Tanzania: CSO Contributions to the Education Sector Review 2006, Dar es Salaam: Tanzania Education Network/Mtandao wa Elimu Tanzania (TEN/MET)

UN (2006) United Nations CRC/C/TZA/CO/2, 21 June

URT (United Republic of Tanzania), Ministry of Labour Youth Development and Sports - Social Welfare Department (2002) 'A Report on the Workshop to Review Laws Related to Child Rights in Tanzania' held at Tanesco Training Centre from 17-18 June, Dar es Salaam

URT (2001) Education Sector Development Programme, Primary Education Development Plan (PEDP), Dar es Salaam: URT

URT (1994) Law Reform Commission (1994) Report of the Commission on the Law Relating to Children in Tanzania, presented to the Minister for Justice and Constitution Affairs, Dar es Salaam

URT, Ministry of Education and Culture (various years) Basic Education Statistics in Tanzania (BEST), Dar es Salaam: URT 